\title{
Music Information Seeking Behaviour among the Students of Humanities and Social Sciences at the University of Osijek
}

\author{
Darko Lacović \\ Faculty of Humanities and Social Sciences, Josip Juraj Strosmayer University of Osijek, Croatia \\ dlacovic@ffos.hr \\ Ivona Palko \\ Faculty of Humanities and Social Sciences, Josip Juraj Strosmayer University of Osijek, Croatia \\ ipalko@ffos.hr \\ Lana Horvatić \\ Faculty of Humanities and Social Sciences, Josip Juraj Strosmayer University of Osijek, Croatia \\ lhorvatic@ffos.hr
}

\begin{abstract}
Summary
The aim of this paper is to give a short overview of some available studies about music information seeking and to present the research that identified music information seeking behaviour among university students. Quantitative methodology was used in the research. An online questionnaire was completed by the students from the Faculty of Humanities and Social Sciences at the University of Osijek (Croatia). The results of the research show that the majority of the respondents search for music information on the Internet (99.2\%), and that they listen to music on smartphones (97.5\%) or computers (90.8\%), using the YouTube application (98.3\%) several times per day $(81.7 \%)$ on average. Most of the students possess their own personal music collection (72.5\%). More than onehalf of the respondents search for music by the performers (65\%) or titles (63.33\%) and prefer rock $(60.8 \%)$ and pop (55\%) music genres. Students indicate that the main reasons for listening to music are entertainment (93.3\%) and decreasing boredom or loneliness (78.3\%).
\end{abstract}

Key words: music information seeking, university students, Faculty of Humanities and Social Sciences, Osijek (Croatia)

\section{Introduction}

Since the beginning of the $21^{\text {st }}$ century, many user studies have been conducted about music information needs, as well as the seeking, searching, browsing and retrieval of music information (for example Lee, Downie, 2004; Weigl, Guastavino, 2011; Hu, Kando, 2017), as well as storage or organization of music collections and music sharing over social media (such as Brinegar, Capra, 2011; Liikkanen, Salovaara, 2015; Lee, Cho, Kim, 2016). Although models of information behaviour are not mentioned in these studies since they are not directly related to the music information seeking, some general models, such as Wilson's models from 1981 and 1997 and Krikelas's (1983) model, can contribute to understanding of the context in which users are searching for music (for example, their motivation or factors for music information needs).

In this paper, authors will present some available studies on music information searching, as well as the research in which they have explored music information seeking behaviour of the students at the Faculty of Humanities and Social Sciences from the University of Osijek (Croatia). This study is rare in that the participants consist exclusively of university students.

\section{Literature review}

There are many studies in which authors examined music information seeking. Lee and Cunningham (2013) analysed the content of 198 user studies and found that in the majority of these studies, authors used various methods (qualitative and quantitative) on a smaller number of participants (in $45 \%$ of the studies from their sample, there were twenty people or fewer). For example, Lee and Downie (2004), 
in their online survey, revealed that the music information seeking of respondents was affected by recommendations or reviews from other people.

Some authors emphasized a user-centred approach for improving music information retrieval (MIR) systems in terms of recommendation tools or visualization interfaces and organization of collection (Schedl, Hauger, 2015; Lee, Price, 2016). Hu and Kando (2017) conducted an experiment on 51 participants who were engaged in MIR. According to their results, task complexity, user background, system affordances, task uncertainty and enjoyability were factors that led to difficulties in music searching. Therefore, these authors concluded these elements should be considered in designing better MIR systems. Moreover, Huron (2000), Dannenberg (2001) and Hofmann-Engl (2001) discussed some music perception models regarding MIR system design, while Schedl, Hauger and Schnitzer (2012) and Zhang et al. (2012) proposed models of serendipity in music retrieval systems.

Other authors were interested in music collections that users own and listen to when studying the process of their music information seeking behaviour. In the study conducted by Cunningham, Reeves and Britland (2003), results showed that the respondents were searching for and browsing popular music in physical collections at record stores or public libraries more than on the Internet. According to the research conducted by Brinegar and Capra (2011) among 184 music users, most of the respondents (75\%) possess their digital music collection, but they also frequently transfer their music on external hard drives or optical mediums. Lee, Cho and Kim (2016), in their larger quantitative survey, revealed that $76.3 \%$ of the respondents owned a digital music collection, while $49.0 \%$ had a physical music collection organized mostly by artist (35.8\% physical vs. $59.8 \%$ digital). $76.5 \%$ of respondents organized their collection using some music management software. Lee, Cho and Kim (2016) also discovered that more than half of respondents (74.5\% from 2004 and 66.5\% from 2012 survey) were avid listeners of music, while around one-third of them were casual listeners $(21.3 \%$ in 2004 and $35.5 \%$ in 2012). The respondents reported that their preferred music genres were rock (18.0\% in 2004), alternative (12.6\% in 2004 and 36.2\% from 2012) and blues (19.6\% in 2012). Most of the respondents indicated that they listened to music on computers (98\%); for entertainment $(94.8 \%$ in $2004,98.4 \%$ in 2012); to build their collection (89\% in 2004, $85.4 \%$ in 2012); to search for online music multimedia (95.1\%); to search the title of the works (91.1\% in 2004, 92.1\% in 2012); to find artist information (76.8\% in 2004, $82.7 \%$ in 2012); to stream music or online radio (77.6\% in 2004 , $96.6 \%$ in 2012); to read any kind of music information ( $86.3 \%$ in $2004,90.0 \%$ in 2012); to purchase and download music files ( $83.1 \%$ in 2012); and to visit online music stores (82.8\% in 2012). The majority of the respondents (80.9\% from the first survey and $82.8 \%$ from the second survey) consulted family or friends when they searched for music information. Bahanovich and Collopy (2009), in their large quantitative study, also revealed that respondents mostly listened to music on their computers every day $(68 \%)$ for the purpose of entertainment.

Many authors found that people use music streaming services such as YouTube, Spotify or Pandora to listen to and share music online (Swanson, 2013; Cesareo, Pastore, 2014; Nguyen, Dejean, Moreau, 2014; Richardson, 2014; Hagen, 2015; Liikkanen, Salovaara, 2015). For instance, Liikkanen and Salovaara (2015) discovered that queries in YouTube searches were mostly related to music and that people often posted comments, voted or shared music. Lee, Cho and Kim (2016) found that $82.2 \%$ of the respondents searched for music they heard on streaming services, while $21.1 \%$ of the respondents used music-related apps (such as Pandora or Spotify) almost every day (13.2\%), or a few times per week (7.9\%). Lee et al. (2017), in their interviews (of 20 adults and 20 teen users), investigated music information behaviour in cloud-based systems and revealed that the most popular cloud services among respondents were Google Play Music, Apple iCloud, Amazon Cloud, Google Drive and Dropbox, which they mostly used for listening to their collections. Furthermore, participants also used streaming sites such as Spotify, Pandora and YouTube for discovering and listening to music for different purposes.

\section{Research methodology}

This study used quantitative methodology. A survey in the form of an online questionnaire was conducted in December 2018 at the Faculty of Humanities and Social Sciences (University of Osijek, Croatia). A total of 120 undergraduate and graduate students participated in the study. The research questions were: 
- What kind of music do students search for and listen to in order to fulfil their information needs?

- What devices and applications do students use for listening to and organizing music?

- How do students search for and find music information online?

The questionnaire was made in Google Forms, posted on Facebook and sent to some participants' email addresses through a Moodle online learning system. It was anonymous and consisted of sixteen mostly closed-ended questions, but the respondents also had the possibility to provide their own answers. The survey collected demographic data about respondents; their music preferences; devices and applications on which they listen to music; their personal music collections; frequency of listening to music; criteria for music searching; reasons for listening to music; and attitudes about music information.

\section{Findings and discussion}

More female (71.7\%) than male students $(28.3 \%)$ participated in the research. The majority of the respondents were 19 and 21 years old (20.8\%), followed by students at the age of 22 (16.7\%), 20 years old (12.5\%), 23 years old (10\%) and 18 years old (8.3\%). Students between 25 and 29 years old were represented the least $(2.5 \%)$. Less than one-half of the respondents were students of library and information science (47.5\%); students of English language and literature (20.8\%); students of Croatian language and literature (19.2\%); students of history (17.5\%); students of education (11.7\%); and students of psychology (10\%).

Regarding the sources of music information, as expected, most of the respondents indicated that they search for music information on the Internet (99.2\%), which is in line with the results that Lee, Cho and Kim (2016) obtained and contrary to the findings of the study conducted by Cunningham, Reeves and Britland (2003). Around one-half of the students search for information about music from friends or colleagues $(59.2 \%)$, while a small number of them look for this information in journals and magazines (10\%), books $(9.2 \%)$ or in libraries $(1.7 \%)$. It can be observed that music has a socialization aspect for the respondents. Results are shown in Table 1.

Table 1. Sources of music information searching

\begin{tabular}{|l|c|}
\hline Information sources & Percentage \\
\hline Internet & $99.2 \%$ \\
\hline friends or colleagues & $59.2 \%$ \\
\hline journals and magazines & $10 \%$ \\
\hline books & $9.2 \%$ \\
\hline libraries & $1.7 \%$ \\
\hline
\end{tabular}

In relation to music genres, more than one-half of the respondents stated that they listen to rock $(60.8 \%)$ and pop (55\%), while around one-third of the students prefer alternative (38.3\%), hip hop or rap $(31.7 \%)$, dance $(30.8 \%)$ and old-time, $\mathrm{R} \& \mathrm{~B}$ or soul $(30 \%)$. This can be understood taking into account the presence of popular music throughout mass media. Around or less than one-quarter of the respondents are interested in classical music $(27.5 \%)$; folk $(25.8 \%)$; blues $(22.5 \%)$; hard rock or heavy metal (20\%); jazz (19.2\%); reggae (17.5\%); Latino (15\%); or new age (14.2\%). $8.8 \%$ of the respondents indicated that they listen to some other music types such as trash, techno, house, punk, experimental music and others, and surprisingly, $8.3 \%$ of the students prefer opera (Table 2). Similar results about music genres preferred by the respondents can be found in the research conducted by Lee, Cho and Kim (2016).

Table 2. Preferred music genres

\begin{tabular}{|l|c|}
\hline Music genres & Percentage \\
\hline rock & $60.8 \%$ \\
\hline pop & $55 \%$ \\
\hline alternative & $38.3 \%$ \\
\hline hip hop or rap & $31.7 \%$ \\
\hline dance & $30.8 \%$ \\
\hline old-time, R\&B or soul & $30 \%$ \\
\hline classical music & $27.5 \%$ \\
\hline
\end{tabular}




\begin{tabular}{|l|c|}
\hline folk & $25.8 \%$ \\
\hline blues & $22.5 \%$ \\
\hline hard rock or heavy metal & $20 \%$ \\
\hline jazz & $19.2 \%$ \\
\hline reggae & $17.5 \%$ \\
\hline Latino & $15 \%$ \\
\hline new age & $14.2 \%$ \\
\hline other & $8.8 \%$ \\
\hline opera & $8.3 \%$ \\
\hline
\end{tabular}

When asked about devices on which students listen to music, the majority of them answered that they use smartphones (97.5\%) and computers (90.8\%). Similar findings were obtained by Bahanovich and Collopy (2009) in their study. Less than half of the respondents listen to music on the radio (46.7\%), and an even smaller number uses tablets $(6.7 \%)$, mp3s or iPods (4.2\%) for listening to music. Interestingly, $1.6 \%$ of the students listen to music on gramophones (Table 3). As expected, most of the respondents use the YouTube platform (98.3\%) for listening to music - probably because it is available for free. This was also confirmed in the study conducted by Liikkanen and Salovaara (2015). Less than one-quarter of the students use music applications such as Soundcloud (24.2\%), Spotify $(17.5 \%)$ and Deezer (9.2\%). These results are also in line with those of Swanson (2013), Richardson (2014), Lee, Cho and Kim (2016), and Lee et al. (2017).

Table 3. Devices for listening to music

\begin{tabular}{|l|c|}
\hline Devices & Percentage \\
\hline smartphone & $97.5 \%$ \\
\hline computer & $90.8 \%$ \\
\hline radio & $46.7 \%$ \\
\hline tablet & $6.7 \%$ \\
\hline mp3 or iPod & $4.2 \%$ \\
\hline gramophone & $1.6 \%$ \\
\hline
\end{tabular}

Further results showed that $72.5 \%$ of the respondents have their own personal music collection and $27.5 \%$ of them do not possess one. Similar results are revealed in studies by Brinegar and Capra (2011) and Lee, Cho and Kim (2016). As can be seen from Table 4, students organize their music collections according to the following criteria: music artist (47.8\%); frequency of listening to music (26.7\%); album (23.3\%); genres (21.1\%); and domestic or foreign music (15.6\%). Only $9.9 \%$ of the students organize their music collection in some other way (for example, according to year, playlist, personal mood, etc.). Most of the respondents indicated that they listen to music several times per day $(81.7 \%)$, and a small number of them listen to music several times per week (17.5\%) or several times per month $(0.8 \%)$. It is obvious that students frequently listen to music, as also revealed by Lee, Cho and $\operatorname{Kim}(2016)$ in their study.

Table 4. Organization of music collection

\begin{tabular}{|l|c|}
\hline Organization criteria & Percentage \\
\hline music artist & $47.8 \%$ \\
\hline frequency of listening to music & $26.7 \%$ \\
\hline album & $23.3 \%$ \\
\hline genres & $21.1 \%$ \\
\hline domestic or foreign music & $15.6 \%$ \\
\hline other & $9.9 \%$ \\
\hline
\end{tabular}

In the question about reasons for listening to music (Table 5), the majority of the respondents answered that they listen to music for fun and entertainment (93.3\%) - which was also confirmed in the study conducted by Bahanovich and Collopy (2009) - as well as for decreasing boredom or loneliness $(78.3 \%)$. Around one-half of the students listen to music when they want to pass the time while they wait for something (51.7\%), or they use music as a background for exercise, such as running or other fitness activities (50.8\%). A smaller amount (9\%) of respondents listen to music for other reasons (for example, when they play games, as background noise or without a specific reason). 
It can be concluded that students actually use music to relax themselves from their academic obligations.

According to research results, $80 \%$ of the students do not know how to play a musical instrument and $20 \%$ do know how to play a musical instrument (15.8\% of the students play string instruments, $3.3 \%$ play drums and electronic instruments, and $1.6 \%$ play percussion). Similar findings are identified by Lee, Cho and Kim (2016).

Table 5. Reasons for listening to music

\begin{tabular}{|l|c|}
\hline Reasons & Percentage \\
\hline fun and entertainment & $93.3 \%$ \\
\hline decreasing boredom or loneliness & $78.3 \%$ \\
\hline to pass the time while waiting & $51.7 \%$ \\
\hline background for exercise & $50.8 \%$ \\
\hline other & $9 \%$ \\
\hline
\end{tabular}

In relation to probability of searching for songs or music information by different elements, more than one-half of the respondents reported that they would certainly search for music by title $(63.3 \%)$ and by performers $(65 \%)$; or, as expected, that they would never search for music by publisher $(52.5 \%)$. More than one-third of the students would rarely search for music according to appearance of the song $(39.1 \%)$, would probably search by popularity of the song $(36.6 \%)$ and would never $(37.5 \%)$ or rarely (35.8\%) search by country. Less than one-third of the respondents would probably search for music by title $(28.3 \%)$; rarely by publisher $(30.8 \%)$; probably by performer; rarely by music popularity (29.1\%); and probably $(25.8 \%)$ or never $(25 \%)$ by appearance of the song. These findings are somewhat different than those from the study by Lee, Cho and Kim (2016). Other results are provided in Table 6.

Table 6. Probability of music searching by different elements

\begin{tabular}{|l|c|c|c|c|}
\hline Elements & Never & Rarely & Probably & Certainly \\
\hline title & $2.5 \%$ & $5.8 \%$ & $28.3 \%$ & $63.3 \%$ \\
\hline publisher & $52.5 \%$ & $30.8 \%$ & $10.8 \%$ & $5.8 \%$ \\
\hline performer & $2.5 \%$ & $5.8 \%$ & $29.1 \%$ & $65 \%$ \\
\hline appearance of the song & $25 \%$ & $39.1 \%$ & $25.8 \%$ & $10 \%$ \\
\hline popularity & $17.5 \%$ & $29.1 \%$ & $36.6 \%$ & $16.6 \%$ \\
\hline country & $37.5 \%$ & $35.8 \%$ & $18.3 \%$ & $8.3 \%$ \\
\hline
\end{tabular}

Regarding the frequency of music information searching over the past month, more than half of the students indicated that they have never searched for information about music publishers $(67.5 \%)$. Around one-third of the respondents answered that they searched for song titles several times per month $(33.3 \%)$ and song publication date once per month (30.8\%), but, also, that they have never searched for information about music genres (30.8\%), albums (37.5\%), date of publishing (39.1\%) or song remixes $(38.3 \%)$. Around one-quarter of the students searched for the following information: song performers several times per month $(27.5 \%)$ and once per month or several times per week (20.8\%); song titles several times per week (21.6\%); music genres once $(25.8 \%)$ or several times per month (20.8\%); album information several times per month $(22.5 \%)$ and once per month $(19.1 \%)$; song lyrics several times per month (26.6\%), several times per week $(23.3 \%)$ and once per week $(19.16 \%)$; and music remixes once per month $(25 \%)$ or several times per month $(21.6 \%)$. Other results are presented in Table 7.

Table 7. Frequency of music information searching

\begin{tabular}{|l|c|c|c|c|c|c|}
\hline Music information & Never & $\begin{array}{c}\text { Once } \\
\text { per } \\
\text { month }\end{array}$ & $\begin{array}{c}\text { Several } \\
\text { times } \\
\text { per } \\
\text { month }\end{array}$ & $\begin{array}{c}\text { Once } \\
\text { per } \\
\text { week }\end{array}$ & $\begin{array}{c}\text { Several } \\
\text { times } \\
\text { per } \\
\text { week }\end{array}$ & $\begin{array}{c}\text { Every } \\
\text { day }\end{array}$ \\
\hline song title & $10.8 \%$ & $10.8 \%$ & $33.3 \%$ & $15 \%$ & $21.6 \%$ & $8.3 \%$ \\
\hline song performer & $10.8 \%$ & $20.8 \%$ & $27.5 \%$ & $10.8 \%$ & $20.8 \%$ & $9.1 \%$ \\
\hline song publisher & $67.5 \%$ & $15.8 \%$ & $10 \%$ & $5.8 \%$ & $2.5 \%$ & $0.8 \%$ \\
\hline genres & $30.8 \%$ & $25.8 \%$ & $20.8 \%$ & $13.3 \%$ & $6.6 \%$ & $2.5 \%$ \\
\hline
\end{tabular}




\begin{tabular}{|l|c|c|c|c|c|c|}
\hline album & $37.5 \%$ & $19.1 \%$ & $22.5 \%$ & $7.5 \%$ & $10 \%$ & $5.8 \%$ \\
\hline song lyrics & $5 \%$ & $10 \%$ & $26.6 \%$ & $19.1 \%$ & $23.3 \%$ & $15.8 \%$ \\
\hline song publication date & $39.1 \%$ & $30.8 \%$ & $17.5 \%$ & $6.6 \%$ & $2.5 \%$ & $5.8 \%$ \\
\hline song remixes & $38.3 \%$ & $25 \%$ & $21.6 \%$ & $8.3 \%$ & $5 \%$ & $1.6 \%$ \\
\hline
\end{tabular}

In the final question, respondents assessed some statements on music information and sources on the scale of 1 to $5(1=$ strongly disagree, $5=$ strongly agree). According to the results (presented in Table 8 ), students mostly agreed with the statement that music information is easy available online (mean = 4.6), and that they encounter music information mostly by accident from different sources (mean = 4.5). Students agreed that they are very satisfied with the music information they find, and that they mainly use music information for fun and entertainment (mean $=4.1$ ). The respondents agreed slightly less with the statement that they rarely find music information in print sources (mean $=3.3$ ), and they agreed least with the statement that they need a lot of time to find music information that they are interested in (mean $=1.9)$. These results are in line with those previously obtained which are related to searching for music information.

Table 8. Agreement to the statements on music information and sources

\begin{tabular}{|l|c|}
\hline Statements & Mean \\
\hline Music information is easy available online & 4.6 \\
\hline I encounter music information mostly by accident in different sources & 4.5 \\
\hline I am very satisfied with the music information I find & 4.1 \\
\hline I mainly use music information for fun and entertainment & 4.1 \\
\hline I rarely find music information in print sources & 3.3 \\
\hline I need a lot of time to find music information I am interested in & 1.9 \\
\hline
\end{tabular}

\section{Conclusion}

The findings of this research show that music information seeking is an important part of students' life activities. It is not surprising that the respondents often search for and find music information online, since music information is available (for free) through different applications. As expected, students mostly search for songs on smartphones by performers and titles for the purpose of entertainment. On the other hand, it is interesting that around $20 \%$ of the respondents look for music information in print sources (books, journals and libraries).

This small and preliminary study is one of the first to deal with music information seeking behaviour among university students in Croatia. It could be seen as a starting point for further investigation, in which a larger number of the respondents from different scientific areas or ages could participate, taking into account some specific aspects of their music information behaviour (for example, a narrow context in which music is retrieved, user requirements of the music information systems, etc.). Moreover, this research can serve as a framework for future studies which could also explore, among many other subjects, the impact of user experience for improving the design of some music applications. It is also recommended to use qualitative methods in order to gain deeper insight into music information behaviour of the users.

\section{References}

Bahanovich, D., Collopy, D. (2009). Music experience and behaviour in young people. London: UKMusic. http://infojustice.org/wp-content/uploads/2011/02/Music-Behavior-in-Young-People-Bahanovich-2009.pdf (24.7.2019)

Brinegar, J., Capra, R. (2011). Managing music across multiple devices and computers. // Proceedings of the iConference 2011. Seattle, WA: ACM, 489-495

Cesareo, L., Pastore, A. (2014). Consumers' attitude and behavior towards online music piracy and subscription-based services. // The Journal of Consumer Marketing 31, 6-7, 515-525

Cunningham, S. J., Reeves, N., Britland, M. (2003). An ethnographic study of music information seeking: Implications for the design of a music digital library. // Proceedings of the Third ACM/IEEE-CS Joint Conference on Digital Libraries. Houston, TX: ACM/IEEE, 5-16

Dannenberg, R. B. (2011). Music information retrieval as music understanding. // Second International Symposium on Music Information Retrieval. Bloomington, IN: ISMIR, 139-142

Hagen, A. (2015). The playlist experience: Personal playlists in music streaming services. // Popular Music and Society 38, 5, 625-645

Hofmann-Engl, L. (2011). Towards a cognitive model of melodic similarity. // Second International Symposium on Music Information Retrieval. Bloomington, IN: ISMIR, 143-151 
Huron, D. (2000). Perceptual and cognitive applications in music information retrieval. // 1st International Society for Music Information Retrieval Conference. Plymouth, $\quad$ MA: 2000. https://www.researchgate.net/publication/220723259_Perceptual_and_Cognitive_Applications_in_Music_Information_ Retrieval (30.10.2019.)

Hu, X., Kando, N. (2017). Task complexity and difficulty in music information retrieval. // Journal of the Association for Information Science and Technology 68, 7, 1711-1723

Krikelas, J. (1983). Information-seeking behavior: Patterns and concepts. // Drexel Library Quarterly 19, 2, 5-20

Lee, J. H., Cho, H., Kim, Y-S. (2016). Users' music information needs and behaviors: design implications for music information retrieval systems. // Journal of the Association for Information Science and Technology 67, 6, 1301-1330

Lee, J. H., Cunningham, S. J. (2013). Toward and understanding of the history and impact of user studies in music information retrieval. // Journal of Intelligent Information Systems 41, 3, 499-521

Lee, J. H., Downie, J. S. (2004). Survey of music information needs, uses, and seeking behaviours: Preliminary findings. // Proceedings of the 5th International Conference on Music Information Retrieval. Barcelona: ISMIR, 441-446

Lee, J. H., Price, R. (2016). User experience with commercial music services: An empirical exploration. // Journal of the Association for Information Science and Technology 67, 4, 800-811

Lee, J. H., Wishkoski, R., Aase, L., Meas, P., Hubbles, C. (2017). Understanding users of cloud music services: Selection factors, management and access behavior, and perceptions. // Journal of American Society for Information Science and Technology 68, 5, 1186-1200

Liikkanen, L. A., Salovaara, A. (2015). Music on YouTube: User engagement with traditional, user-appropriated and derivative videos. // Computers in Human Behavior 50, 108-124

Nguyen, G., Dejean, D., Moreau, S. (2014). On the complementarity between online and offline music consumption: The case of free streaming. // Journal of Cultural Economics 38, 4, 315-330

Richardson, J. H. (2014). The Spotify paradox: How the creation of a compulsory license scheme for streaming on-demand music platforms can save the music industry. // UCLA Entertainment Law Review 2, 1, 45-74. https://escholarship.org/content/qt7n4322vm/qt7n4322vm.pdf?t=n15jht (24.7.2019)

Schedl, M., Hauger, D., Schnitzer, D. (2012). A model for serendipitous music retrieval. // Proceedings of the 2nd International Workshop on Context-awareness in Retrieval and Recommendation (CaRR 2012). Lisbon: ACM, 10-13

Schedl, M., Hauger, D. (2015). Tailoring music recommendations to users by considering diversity, mainstreaminess, and novelty. // Proceedings of the 38th International ACM SIGIR Conference on Research and Development in Information Retrieval. New York: ACM, 947-950

Swanson, K. (2013). A case study on Spotify: Exploring perceptions of the music streaming service. // Journal of the Music \& Entertainment Industry Educators Association 13, 207-230. http://www.meiea.org/resources/Journal/Vol.13/Swanson-MEIEA_Journal_vol_13_no_1_2013-p207.pdf (24.7.2019)

Weigl, D. M., Guastavino, C. (2011). User studies in the music information retrieval literature. // Proceedings of the 12th International Society for Music Information Retrieval Conference. Miami, Florida: ISMIR, 335-340

Wilson, T. D. (1997). Information behaviour: an interdisciplinary perspective. // Information Processing \& Management 33, 4, 551-572

Wilson, T. D. (1981). On user studies and information needs. // Journal of Documentation 37, 1, 3-15

Zhang, Y. C., Seaghdha, D. O., Quercia, D., Jambor, T. (2012). Auralist: Introducing serendipity into music recommendation. // Proceedings of the 5th ACM International Conference on Web Search and Data Mining (WSDM). Seattle, WA: ACM, 13-22 